\title{
Management of a growing dog with renal failure fed a homemade diet
}

Gerstner, Kerstin ; Liesegang, Annette

DOI: https://doi.org/10.17236/sat00099

Posted at the Zurich Open Repository and Archive, University of Zurich ZORA URL: https://doi.org/10.5167/uzh-133385

Journal Article

Published Version

Originally published at:

Gerstner, Kerstin; Liesegang, Annette (2016). Management of a growing dog with renal failure fed a homemade diet. Schweizer Archiv für Tierheilkunde, 158(12):834-836.

DOI: https://doi.org/10.17236/sat00099 


\title{
Management of a growing dog with renal failure fed a homemade diet
}

\author{
K. Gerstner, A. Liesegang \\ Institute of Animal Nutrition, Vetsuisse Faculty, University of Zurich, Switzerland
}

DOI 10.17236/sat00099

Received: 29.02 .2016 Accepted: 30.05 .2016

\section{Introduction}

Renal failure in growing dogs occurs if damaged tissue of the kidneys fails to effectively clear the blood from urinary excreted substances (e.g. urea, creatinine, phosphorus). Increasing blood levels of proteinaceous catabolites lead to typical symptoms depending on severity of renal failure. Abnormalities found in blood and urine analysis are azotaemia, hyperphosphataemia, non-regenerative anaemia and proteinuria. Impaired growth and skeletal abnormalities occur in immature dogs with renal failure due to secondary hyperparathyreoidism (Lees, 1996; Cortadellas et al., 2010). Dietary management of renal failure includes restricted supply of phosphorus and nonessential proteins but feeding protein sources with a high digestibility and bioavailability providing essential amino acids is crucial (Devaux et al., 1996). Patients benefit from decreasing oxidative stress by decreasing renal hypertension (medication) and ensuring the supply with antioxidants like vitamin $\mathrm{E}$ and C (Yu et al., 2006). The supply of potential anti-inflammatory omega 3 fatty acids (eicosapentaenoic acid and docosahexaenoic acid; Brown et al., 2000) are recommended although the potential effect is controversially discussed in pets (Lenox et al., 2013). Feeding a commercial renal diet for adult dogs to a growing dog leads to deficits for protein and minerals, impairing bone metabolism, muscle growth or even basal metabolic functions. As recommendations of protein and amino acid supply for a growing dog suffering from chronic renal failure have not been established, the aim of this report was to establish an individual dietary approach depending on age, breed and state of the kidney disease.

\section{Case history}

Due to azotaemia a 8 months old female, intact Labrador Retriever with a body weight of $17.5 \mathrm{~kg}$ and an estimated adult weight of $23 \mathrm{~kg}$ was referred to the nutrition consultation service of the Institute of Animal Nutrition, University of Zurich 2 months after surgical cor- rection of both sided ectopic ureters. Blood analysis revealed that the azotaemia increased post surgically (Urea $21.5 \mathrm{mmol} / \mathrm{l}$, creatinine $303 \mu \mathrm{mol} / \mathrm{l}$ ). We speculate that the increase of azotaemia occurred due to pre-surgical severe kidney damage, which the dog was not able to compensate. The owner asked for the calculation of a homemade diet, which covers the recommendations of this growing dog and protects the kidneys at the same time.

\section{Diet calculation}

Nutrient supply at the time point of consultation with a commercial diet for growing dogs (Novafoods Fitness Trainer Junior medium/ maxi; approximately $225 \mathrm{~g}$ per day $=$ current diet) and a variety of different treats were calculated with a diet calculation software (Diet Check Munich (C2005, Unterschleissheim, Germany; Tab. 1). Recommendations of the NRC (National Research Council, 2006) and the GfE (Deutsche Gesellschaft für Ernährung) were met for protein but not for calcium and phosphorus (Tab. 1). Information on magnesium, potassium and sodium content were not provided by the feed company (Novafoods, Castelgomberto, Italy). The dog's current body weight was within an ideal range on the calculated growth curve (Puppy growth check $\mathbb{C}$, 1998, Munich, Germany; Fig. 1). Therefore, the energy supply was assumed to cover the individual needs of the dog and this energy supply was used for the calculation of the recommended diet since the dog had an ideal body weight. Energy requirements corresponded to values estimated by the equation of Blanchard et al., (1998). As the azotaemia was progressive, the protein supply in the recommended diet was decreased to an amount, which covered minimum requirements (Tab. 1). The homemade diet was based on beef and cottage cheese (animal protein) to provide essential amino acids. The owner was instructed to use meat with a high fat content and to refrain from feeding innards or other feed containing high amounts of connective tissue. It has been shown that phosphate binders are only efficient if fed 
additionally to a renal diet with a reduced phosphorus content (Zatelli et al., 2012). As blood levels of phosphorus were within the normal range for a growing dog, dietary phosphorus supply was not reduced in this patient and phosphate binders were not indicated. To provide vitamin $\mathrm{E}$ and omega 3 fatty acids, linseed oil and salmon oil was included in the diet. Oils as well as rice provided energy without increasing the protein content of the diet. Vegetables and a mineral supplement covered the need for fibre, minerals and vitamins (Tab. 1).

\section{Follow-up control}

Unfortunately the owner neither followed the recommendations on dietary supply nor on the management. The diet was changed by the owner and was not fed as recommended. According to the referring veterinarian urea $(34.2 \mathrm{mmol} / \mathrm{l})$ and creatinine $(550 \mathrm{\mu mol} / \mathrm{l})$ concentrations in the blood increased and a non-regenerative anaemia (haematocrit 38.3\%) was detected with the age of 10 months. At that time, the owner changed the diet partially to a dry commercial renal diet mixed with a homemade diet. At the age of 1 year proteinuria (UPC 1.81) implemented a progressive impairment of the renal function. The dog was euthanized with the age of $1 \frac{1 / 2}{2}$ years.

\section{Discussion}

Feeding a homemade diet to a growing dog suffering from chronic renal disease requires a good owner compliance. Recommendations need to be followed tightly and frequent check-ups are important. The nutritional

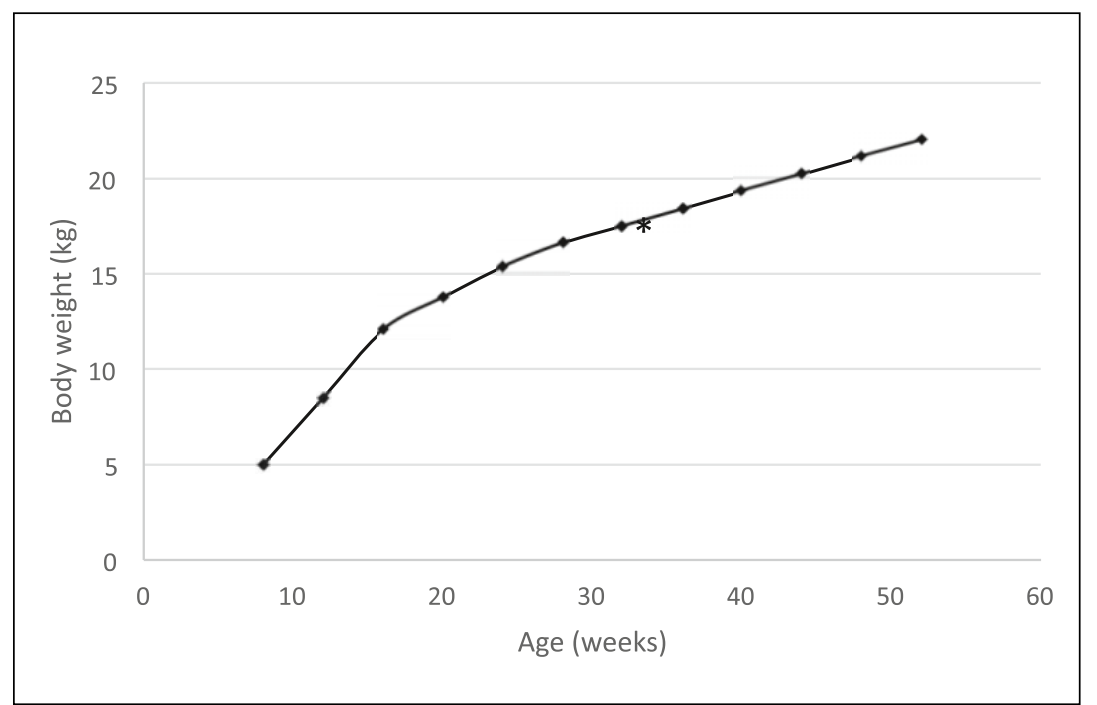

Figure 1: Calculated growth curve of a female Labrador Retriever with an estimated adult weight of $23 \mathrm{~kg}$ and $17.5 \mathrm{~kg}$ at the age of 33 weeks.

management of a patient with renal failure includes a regular and consistent feeding pattern and high water intake. Dietary adaptations are required if blood levels of creatinine, urea or phosphorus increase (Bartges, 2012), if body weight changes divergent of the calculated growth curve and as soon as the dog reaches the age of one year. An ideal nutrition retards the progress of a renal disease. To ideally support this patient, more frequent check-ups and further dietary adaptations according to changes in blood values and growth would have been required. The fulfilment of dietary requirements of a growing dog and at the same time protecting diseased kidneys is difficult. Commercial renal diets are not adaptable to meet the requirements of a growing

Table 1: Nutrient requirements and nutrient supply of the patient. Minimum requirement (support of physiological state only possible if nutrients have a high bioavailability), adequate intake and recommended allowance (nutrient amount to support a given physiological state; = adequate intake or minimum requirement including bioavailability factor) according to NRC 2006, nutrient supply with the current diet and the recommended homemade diet. \#recommended allowance was adapted according to the GfE.

\begin{tabular}{|c|c|c|c|c|c|}
\hline Daily amount per dog & $\begin{array}{l}\text { Minimum } \\
\text { requirement }\end{array}$ & $\begin{array}{l}\text { Adequate } \\
\text { intake }\end{array}$ & $\begin{array}{l}\text { Recommended } \\
\text { allowance }\end{array}$ & Current diet & $\begin{array}{c}\text { Recommended } \\
\text { diet }\end{array}$ \\
\hline Energy (MJ ME) & - & - & 4.7 & 4.4 & 4.5 \\
\hline Crude protein $(\mathrm{g})$ & 52 & - & 83\# & 81 & 69 \\
\hline Calcium (g) & 3 & - & 4.4 & 2.7 & 4.9 \\
\hline Phosphorus (g) & - & 3.7 & 3.7 & 2.1 & 3.7 \\
\hline Magnesium (mg) & 66.6 & - & 148 & $?$ & 220 \\
\hline Potassium (g) & - & 1.6 & 1.6 & $?$ & 1758 \\
\hline Sodium (mg) & 814 & - & 814 & $?$ & 843 \\
\hline Vitamin A (IE) & - & 1495 & 1870 & 6497 & 2817 \\
\hline Vitamin D (IE) & 163 & - & 201 & 348 & 310 \\
\hline Vitamin $E(m g)$ & 8.9 & - & 11 & 293 & 29 \\
\hline
\end{tabular}


Management of a growing dog with renal failure fed a homemade diet

K. Gerstner, A. Liesegang dog. A homemade diet is easily adjustable to changing requirements due to growth and progression of the disease.

\section{Conclusion}

An individual dietary recommendation calculated by a veterinary nutritionist and a good owner compliance in combination with an intense collaboration of the practitioner are obligatory to provide an optimal support of the health of a growing dog with renal failure.

\section{References}

Bartges, J. W.: Chronic Kidney disease in Dogs and Cats. Vet. Clin. North Small Anim. Pract. 2012, 42: 669-692.

Blanchard G., Grandjean D., Paragon B. M.: Calculation of a dietary plan for puppies. J. Anim. Physiol. Anim. Nutr.1998, 80: 54-59.

Brown S. A., Brown C. A., Crowell W. A., Barsanti, J. A., Kang C. W., Allen T., Cowell C., Finco, D. R.: Effects of dietary polyunsaturated fatty acid supplementation in early renal insufficiency in dogs. J. Lab. Clin. Med. 2000, 135: 275-286.

Cortadellas O., del Palacio M. J. F., Talavera J., Bayon A.:

Calcium and phosphorus homeostasis in dogs with spontaneous chronic kidney disease at different stages of severity. J. Vet. Intern. Med. 2010, 24: 73-79.

Devaux C., Polzin D. J., Osborne C. A.: What role does dietary protein restriction play in the management of chronic renal failure in dogs? Vet. Clin. North Small Anim. Pract. 1996, 26: 1247-1267.

Lees G. E.: Congenital renal diseases. Vet. Clin. North Small Anim. Pract. 1996, 26: 1379-1399.

Lenox C. E., Bauer J. E.: Potential adverse effects of omega-3 fatty acids in dogs and cats. J. Vet. Intern. Med. 2013, 27: 217-226.

National Research Council (NRC): Nutrient Requirements of Dogs and Cats. The National Academies Press. 2006.

Yu S., Pateau-Robinson I.: Dietary supplements of vitamins $\mathrm{E}$ and $\mathrm{C}$ and beta-carotene reduce oxidative stress in cats with renal insufficiency. Vet. Res. Commun. 2006, 30: 403-413.

Zatelli A., Pierantozzi M., D'lppolito P, Bigliati M., Zini E.: Effect of dietary supplements in reducing probability of death for uremic crises in dogs affected by chronic kidney disease (masked RCCT). ScientificWorldJournal. 2012, 2012: 219082.

\section{Correspondence}

Prof. Dr. med. vet. Annette Liesegang

Dipl. ECVCN, Dipl. IVAS, Institute of Animal Nutrition

Vetsuisse Faculty, University of Zurich

Winterthurerstrasse 270

8057 Zürich

Switzerland

Phone: 0041446358823

Fax: 0041446358939

E-Mail: aliese@nutrivet.uzh.ch 